\title{
Digital database on shrimp farming in coastal watershed of Cuddalore District, Tamil Nadu
}

\author{
P. NILA REKHA, R. GANGADHARAN, SHIRLEY DHARSHINI, WILMART CLARK, \\ G. RAMANATHAN, DEBORAL VIMALA, A. PANIGRAHI AND C. GOPAL \\ ICAR-Central Institute of Brackishwater Aquaculture, 75, Santhome High Road, R. A. Puram, Chennai- 600028 \\ Tamil Nadu, India \\ e-mail:rekha@ciba.res,nila_71@yahoo.com
}

\begin{abstract}
Brackishwater shrimp farming is essentially a coastal farming activity, making use of the marginal land and water resources resulting in economic benefits, providing livelihood option for the coastal poor and contributing to the national GDP. Getting successful crop by the farmers is indeed a great accomplishment since the disease threat always hovers around shrimp culture. This warrants the adoption of better management practices starting from the pond construction till the harvest of the shrimp with a collective action among the shrimp farmers in a cluster of farms with respect to stocking, adoption of biosecurity measures, disease management and discharge of treated water. For practically enforcing this through farmers' associations, development of spatial database is a prerequisite and it is a relatively easy task in this age of information revolution. With this background, a digital information system has been built using ArcGIS 10.0 for the shrimp farms in the coastal watershed of Cuddalore District in Tamil Nadu primarily to aid farmers. The developed spatial database contains information about all the shrimp farms in Cuddalore District and it has been digitised from GeoEye with the cadastral map in the scale of 1:5000. A total of $4 \mathrm{~km}^{2}$ of shrimp farm area with 351 individual ponds spread over six clusters of farms has been digitised with their survey number. Field surveys were conducted to verify the satellite data. Details of the farms'were collected using a structured questionnaire and have been incorporated in the database. Using this database both spatial and statistical information can be analysed and managed for querying, decision making and resource management. This digital information will also be handy for the policymakers for licensing the farm, monitoring growth and to enforce environmental guidelines.
\end{abstract}

Keywords: Coastal watershed, Digital information system, GIS, Shrimp farming

\section{Introduction}

Coastal aquaculture aims at deriving maximum benefits from unproductive and marginally productive coastal lands and brackishwater bodies and it has contributed significantly to the progress of country's economy as well as the economic well-being of the rural poor. India, by virtue of its $8129 \mathrm{~km}$ long coastline covering nine coastal states and four union territories with varied terrain and climate, supports a wide diversity of coastal wetland habitats. There are 14 major river systems in the country which have led to the formation of wide network of creeks and estuaries in coastal regions of the country, facilitating coastal aquaculture. It has also been estimated that about 1.2 million ha of potential brackishwater area available in India is suitable for brackishwater aquaculture. However, the total area under brackishwater farming is only just over $15 \%$ of the potential water area available (CIBA, 2012). To meet the great challenge of utilising this vast resource in a sustainable manner, systematic planning is absolutely necessary. This requires detailed information about the existing farms and this prompted the present study on development of database for shrimp farming. Moreover, if the information system is watershed based, it would be even more beneficial as watershed based aquaculture planning and development of shrimp farming would be appropriate (Rekha et al., 2013). In addition to planning, identification and control of disease spread as well as monitoring the growth of aquaculture in individual ponds require the basic database. Since it is essentially spatial as the differences among biophysical and socio-economic characteristics from location to location, geographic information system (GIS) and remote sensing could be best utilised to get the desired results.

The GIS is an integrated assembly of computer hardware, software and geographic data to efficiently acquire, store, manipulate, retrieve, analyse, display and report all forms of geographically referenced information geared towards a particular set of purposes (Burrough, 1986; Kapetsky and Travaglia, 1995). It has been used in aquaculture since the mid-1980s both for brackishwater aquaculture (Mohamed et al., 2010) and inland aquaculture (Meaden and Kapetsky, 1991). Nath et al. (2000) gave a detailed review on the potential application of GIS and 
remote sensing in the field of aquaculture. They have also evaluated the potential applications of GIS for spatial decision support (SDS) in aquaculture and enumerated constraints in wide application of SDS among aquaculture community. Moreover, environmental impact assessment can be carried out accurately using GIS and remote sensing as it will give holistic and realistic scenario (Rajitha et al., 2007; Rekha et al., 2015).

The latest digital technologies like remote sensing and GIS could help for the better management of shrimp farming by providing spatial information to the decision makers in terms of biophysical and socioeconomic characteristics which are needed for aquaculture planning and management for sustainable use of available resources (Kapetsky and Travaglia, 1995). However, increased deployment of GIS for practical decision making in aquaculture is hampered by several constraints including lack of appreciation of the benefits of such systems on the part of key decision-makers; limited understanding about GIS principles and associated methodology; inadequate administrative support to ensure GIS continuity among organisations; and poor levels of interaction among GIS analysts, subject matter specialists and end users of the technology. However, nowadays, application of GIS by government departments is on the increasing trend. New information sources also shorten the time from project planning to development of operational database, with most important practical application being implemented to the level of municipal administration. The global positioning system (GPS) has revolutionised field data collection in areas ranging from surveying to environmental monitoring and transportation management. A new generation of commercial, high-resolution satellites promises pictures of nearly any part of the earth's surface with enough detail to support numerous mapping applications.

The present study demonstrates the possible application of satellite remote sensing and geographical information system (GIS) for giving information to farmers and the policy makers about the details of the farming to assist in planning, to carry out development and to implement best management practices in shrimp farms.

\section{Materials and methods}

Study area

For the present study, the area located between $11^{\circ} 30^{\prime} \mathrm{N}$ to $11^{\circ} 20^{\prime} \mathrm{N}$ latitude and $79^{\circ} 38^{\prime} \mathrm{E}$ to $79^{\circ} 48^{\prime} \mathrm{E}$ longitude in Cuddalore District, Tamil Nadu, was selected since aquaculture is being practiced in the area since early nineties. This study area falls within the survey of India Toposheet no. $58 \mathrm{M} / 15$ and 16. To develop the database on the watershed basis, three adjacent mini-watershed areas with two in Lower
Vellar sub-watershed (4C1A1c4a4 and 4C1A1c3b1) and one in Coleroon watershed (4B1A5a1ble) were selected in Cuddalore District, Tamil Nadu and delineated using ARC GIS.10 (Fig. 1). The total extent of the study area was about $213.458 \mathrm{~km}^{2}$ and about $4 \mathrm{~km}^{2}$ area is covered by shrimp farms. The detailed methodology is shown in Fig. 2.

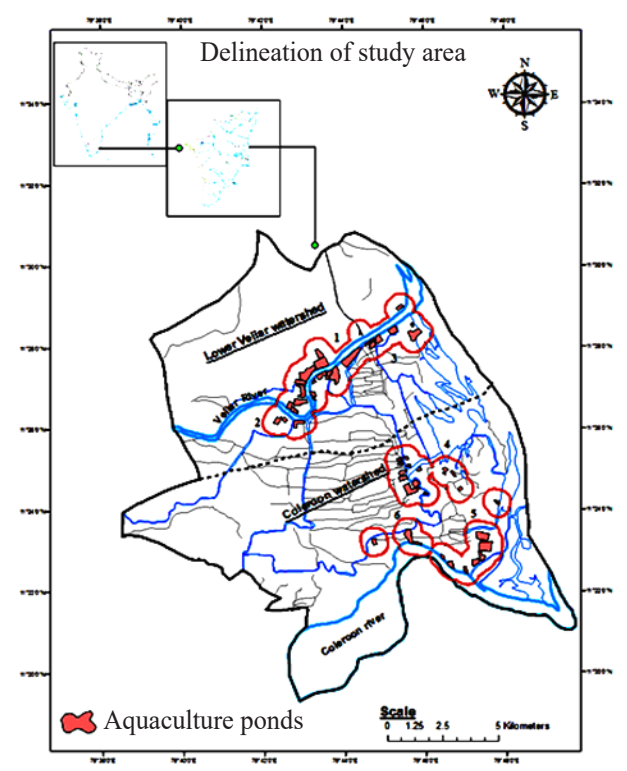

Fig. 1. Location map

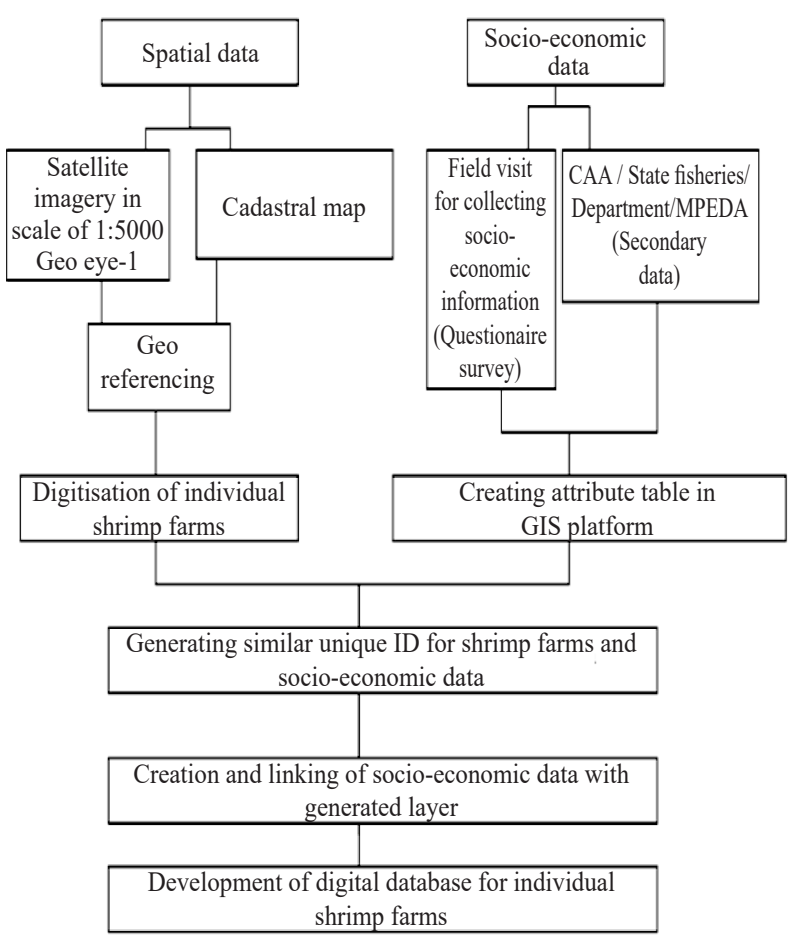

Fig. 2. Flow chart of methodology for the development of digital database 


\section{Cadastral maps}

Cadastral map of the selected coastal village were obtained from the Revenue Department, Cuddalore District, Govt. of Tamil Nadu. The scanned image of the cadastral map was later automated into vector GIS layer (Fig. 3) after image rectification and geo-referencing with the help of many ground control points (GCP) uniformly spread in the whole region.

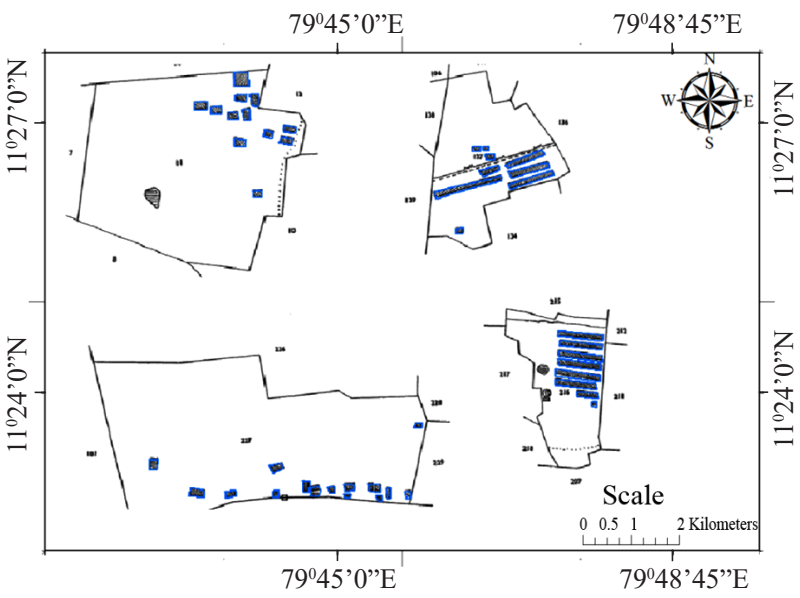

Fig. 3. Cadastral maps in GIS environment

\section{Digitisation of shrimp farms on satellite imagery}

The selected areas under study were geo-referenced from the GeoEye 1 and Landsat satellite images. Later the village cadastral maps were registered to the satellite imagery (Fig. 4). This helped in perfectly matching the survey number of the village map with the satellite image. Individual farms were then digitised from the imagery. In order to collect the socio-economic data, field survey was conducted. Data related to farm identification, aquaculture license number, ownership detail,

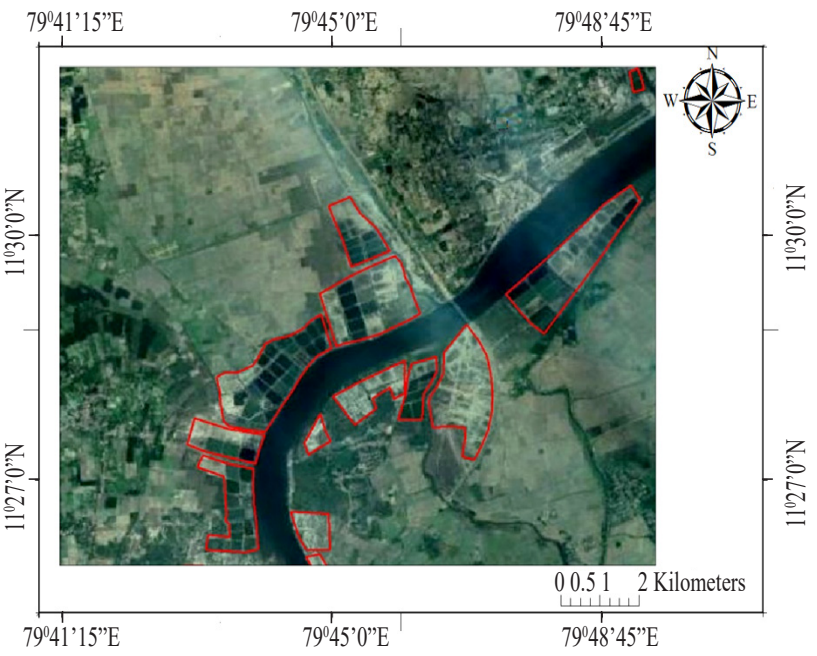

Fig. 4. Satellite image showing individual shrimp farms number of ponds and size of farm were obtained from Coastal Aquaculture Authority and Marine Products Export Development Authority (MPEDA), Thanjavur, Tamil Nadu.

\section{Design of digital database}

The present design of digital data was developed with the consideration that it should be application oriented and user friendly which can be shared by different users. This database enables various methods of data access, storage of data independent of application, control access to data, facilitate data modification, and minimise data redundancy. The content of the database plays an important role in the overall design of the system and depends upon the users and desired applications of the database. The size of a database is a function of its content; more the information needed, the larger the database.

The present database is mainly to cater the needs of the shrimp farmers in the watershed to operate sustainable disease free farming. The first step in this database development was to have spatial information about the study area such as drainage pattern, soil texture, geomorphology, lithology and landuse/landcover. Second step was to have farm information and final step to have individual pond information. One of the important components of the database system is the database management system. This system is used to control the storage, retrieval and modification of the data, file handling and management being one of its functions. It protects the integrity of data and keeps track of the record, each time the system is used and provides recovery and backup procedures. Moreover for the database to be useful, it has been designed with provision to upgrade in such a manner that it takes care of future expansion and adaptability. In database monitoring, the system can be fine-tuned with provision for any addition and deletion to keep it as a valid database. Accordingly, this database was designed, information collected and stored in GIS environment

\section{Integration and linkage of socio-economic attribute data}

Geographic data is the composite of spatial and attribute data. Secondary data were collected from MPEDA and these were digitised spatially using ArcGIS. Groundtruth (GT) data in selected micro-watershed were collected in each survey number using the digitised village maps and superposed on satellite digital data. Data on farm census were collected as explained earlier. The socio-economic data about each shrimp farms in the study area was collected through structured interview schedule. The various details collected about the farm are sources of water; water spread area; water discharge area; water saline condition; total farm area; total number of ponds; distance of farm from the sea, creek, agricultural land and village; type of farming; species cultured; no. of crops in the year; farms under culture; 
distance between pumping point and drainage point; no. of success and failure of cultures during previous year; feed and other inputs and previous use of the land. The geographic coordinates of these sites were also recorded using differential GPS. After collecting data from field, the data were entered into attribute table in GIS environment as shown in Fig. 5 and stored.
The farmers' perception about the groundwater quality was also recorded. All these data have been integrated using GIS technique and geo-database which will help the farmers to plan their processing and marketing operations so as to achieve better remunerations. This analysis will also help the farmers to identify potential areas for shrimp farms.

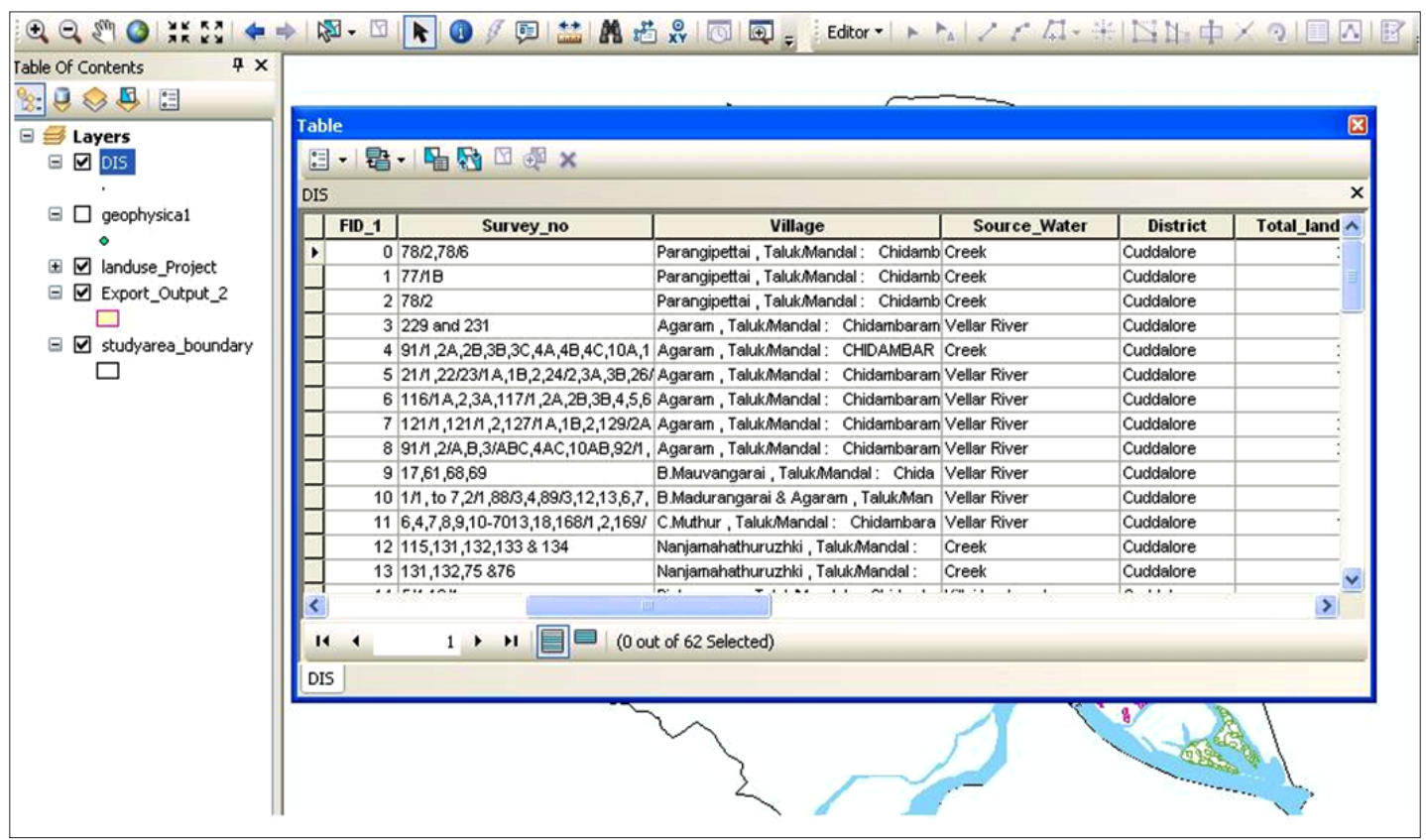

Fig. 5. Socio-economic data in GIS environment

Each row in the attribute table which is in the form of a spreadsheet, is a record. Each column in the table is called a field. It gives the description about farms in detail and in this database, 18 columns have been included which means 18 parameters describing the farms. It is to be noted that columns can be added in future as and when required. The GIS application links the attribute records with the feature geometry so that one can find records in the table by selecting features on the map, and find features on the map by selecting features in the table. Therefore, details of 351 ponds are available with click of mouse at the individual pond in the spatial database. The unique ID-number along with ownership of an individual farmer was generated for individual aqua-farms identified on GeoEye-1 and Landsat merged images. The socio-economic data collected were linked with these individual farms in the GIS environment. Using this databases, both spatial and statistical information can be analysed and managed for querying, decision making and resource management. This digital information will also be handy for the policymakers for licensing the farm, monitoring growth as well as to enforce the environmental guidelines.

\section{Results and discussion}

Development of the comprehensive microwatershedbased database was mainly carried out to assist shrimp farmers and the policy makers. Various thematic maps such as drainage, soil texture, geomorphology, lithology and landuse/landcover in spatial format have been prepared in ArcGIS 1.0 which form the basis of the database (Fig. 6a-e). The drainage map (Fig. 6a) of the study area shows that it was covered by parallel drainage system with Vellar River in northern side and Coleroon River in southern side and its tributaries distributing throughout the study area. Soil texture of the study area (Fig. 6b) is of sandy clay loam (SCL), clay loam (CL) and loamy soil (LS). The geomorphology map (Fig. 6c) shows the presence of younger coastal plain (YCP), older coastal plain (OCP) and alluvial plain (AP ). The study area was mainly surrounded by sedimentary formation and it consists of fluvial flood basin (FFB), marine tidal flat (MTF) and marine lagoon (ML) (Fig. 6d).

The major landuse pattern in the study area (Fig. 6e) includes vegetation $(\mathrm{V})$, barren land $(\mathrm{BL})$, built-up land (BUL) and water bodies (WB) in addition to shrimp ponds 


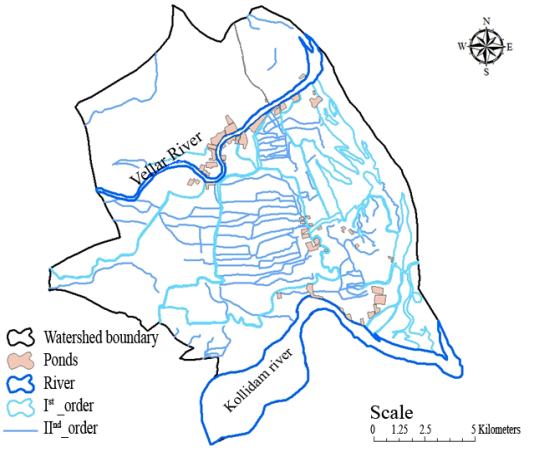

(a)

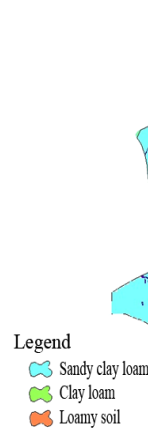

C) Loamy soil

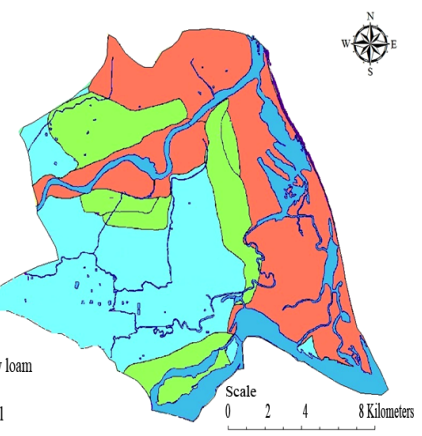

(b)

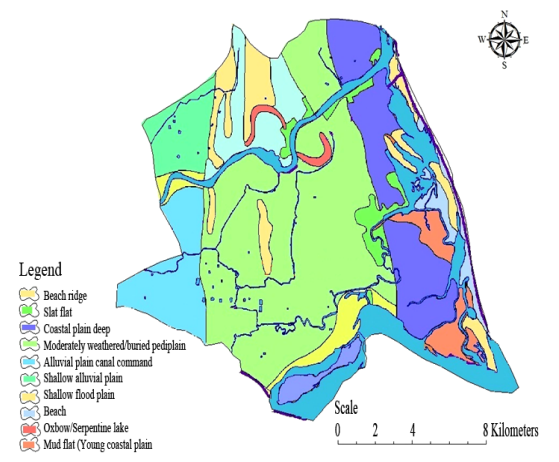

(c)

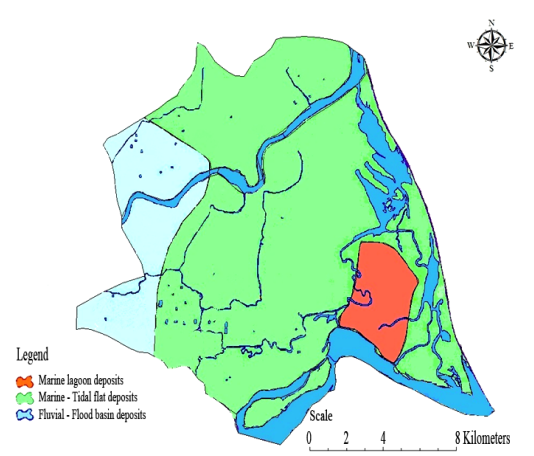

(d)

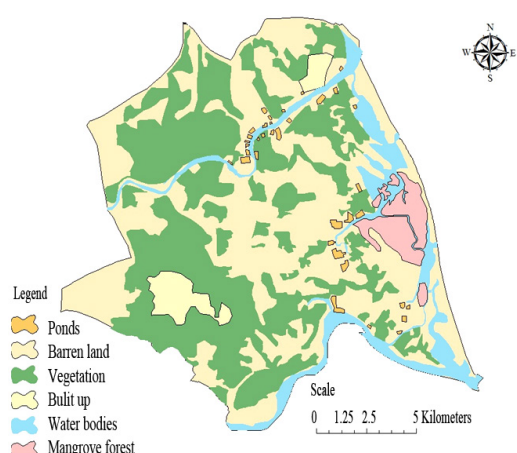

(e)

Fig. 6. (a) Drainage map, (b) Soil map, (c) Geomorphology map, (d) Lithology map, (e) Landuse and landcover map

and mangrove forest. Total shrimp farming area in the study area is about $4 \mathrm{~km}^{2}$ with six clusters (Table 1). It could be observed that more ponds were in Lower Vellar watershed $\left(2.57 \mathrm{~km}^{2}\right)$ compared to Colleroon watershed $\left(1.53 \mathrm{~km}^{2}\right)$.

Table 1. Shrimp farm cluster details

\begin{tabular}{lll}
\hline Total cluster & Total area $\left(\mathrm{km}^{2}\right)$ & Total no. of ponds \\
\hline I Cluster & 1.02 & 62 \\
II Cluster & 0.38 & 23 \\
III Cluster & 1.00 & 46 \\
IV Cluster & 0.68 & 60 \\
V Cluster & 0.90 & 140 \\
VI Cluster & 0.08 & 20 \\
\hline
\end{tabular}

About 351 ponds are in operation and a total of 61 shrimp farmers own these ponds. The socio-economic data about each shrimp farm in the study area can be obtained from the GIS database. In this database, 61 rows as records were stored as there were 61 shrimp farms. The farmers who own more than 2 ha, are considered as big farmers and the database shows that only $37.1 \%$ belong to the category of big farmers, whereas, about $62.9 \%$ come under small farmers' category as their water spread area is less than 2 ha. Other details of farmers can also be easily retrieved. The database was designed as per the user's requirements and accordingly, it can be organised and managed.
The shrimp farming system especially in the study area comes under only extensive to semi intensive category. Shrimp farming was initiated in Killai area of the watershed in early nineties and has expanded slowly. The study site infact is in rainfed area and agriculture was done based on the rainfall availability. Aquaculture is a profitable venture, yielding 50 to $80 \%$ rate of return per annum, much beyond the returns that can be expected from any other activity in this coastal area. Unemployed coastal folks and agriculturists are offered jobs in the aqua-farms for wages that far exceed those in other farming activities in the study area and as a new activity it developed curiosity and interest among the farmers. Thus, aquaculture has expanded to about 400 ha in the study area till date. In addition to aquaculture, agriculture is widely practiced in the watershed. The land use map clearly gives the activities in the watershed and only $2 \%$ of the study area comes under aquaculture. More than aquaculture, agriculture is the dominant activity in the watershed. Wherever agriculture was not able to thrive, aquaculture was introduced. However, the investment for initiation of aquaculture is more when compared to agriculture.

As with many computer based systems, the key to GIS success lies in acquiring suitable geographic data, information describing the location and attributes of object, including their shape and representation. Using the digital data interface, the user can get the required information through 
a click of mouse (Fig. 7). Similar types of digital databases have been developed for the coastal district of Gujarat (Singh et al., 2012) with high resolution satellite data wherein, it has been ascertained that the database has not only helped in identifying suitable area for shrimp culture but also aid to benefit the farmer as it helped them to get better remunerations by increasing their entrepreneurship skills. In the same line, the present study demonstrated the capability of RS and GIS techniques to identify and delineate the brackishwater resources and potential areas that are sustainable for shrimp farm development even with the Google Earth, as the satellite data source for the present study is only Google Earth. The accuracy assessment of the techniques were evaluated based on the ability of farm identification and was found to be precise and can be used for field studies.

The present study has demonstrated that recent technologies like satellite remote sensing and the GIS technology can aid in the sustainable management of shrimp culture through Geo-referencing of satellite data and cadastral maps as well as by linking the socio-economic data collected through field survey. The digital information system on shrimp farms developed in the present study will enable managers and planners to determine the extent of shrimp farming activities, as well as provides a platform for recording and viewing environmental data over space and time and thereby to enforce sustainable shrimp farming.

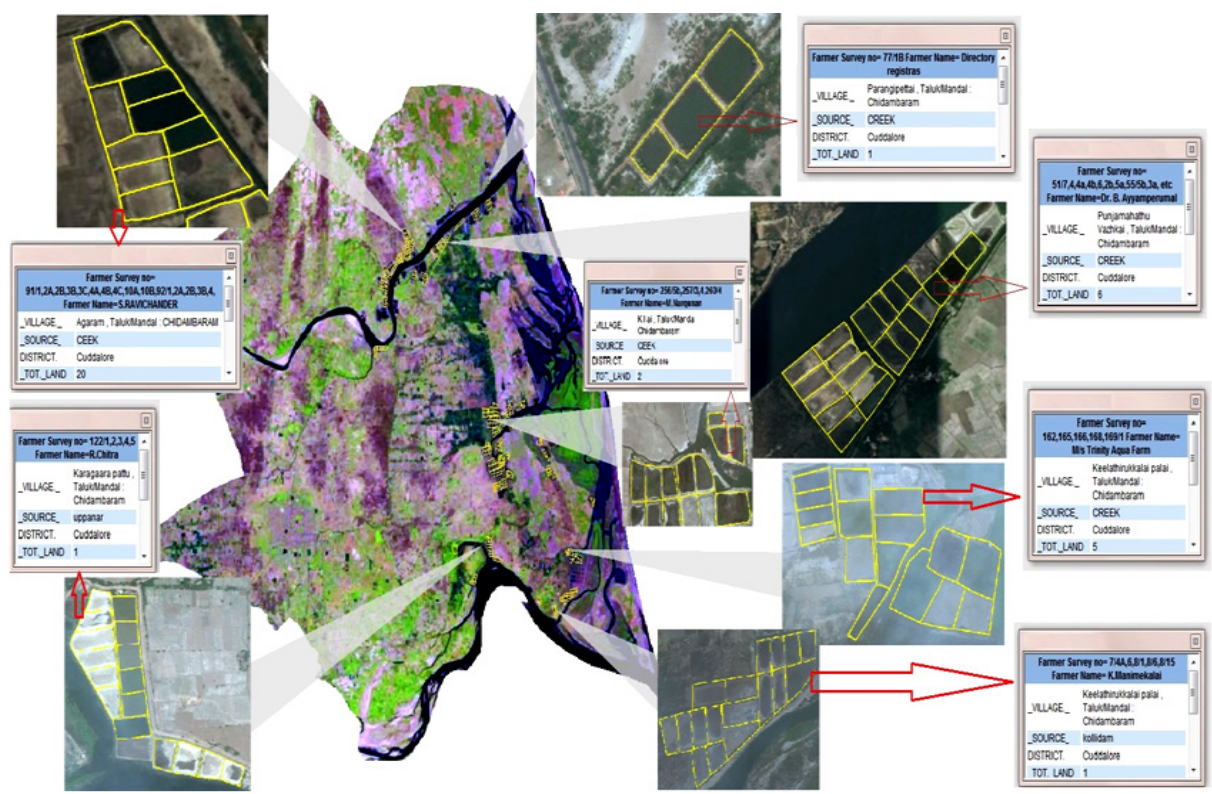

Fig. 7. Details of digital database of shrimp farms

\section{Acknowledgements}

The first author is extremely thankful to the Ministry of Water Resources, Government of India for the financial assistance for this study.

\section{References}

Burrough, P. A. 1986. Principles of geographic information systems, $1^{\text {st }}$ edn. Oxford University Press, New York, 336 pp.

CIBA 2012. Annual Report 2011-2012. Central Institute of Brackishwater Aquaculture, Chennai.

Kapetsky, J. M. and Travaglia, C. 1995. Geographical information systems and remote sensing: an overview of their present and potential applications in aquaculture. In: Nambiar, K. P. P. and Singh, T. (Eds.), AquaTech '94: Aquaculture towards the $21^{\text {st }}$ Century. INFOFISH, Kuala Lumpur, Malaysia, 187-208

Meaden, G. J. and Kapetsky, J. M. 1991. Geographical information system and remote sensing in inland fisheries and aquaculture
- Food and Agricultural Organisation of the United Nations, FAO fisheries technical paper No. 318, FAO, Rome.

Mohamed, K. S., Prvin, P., Asokan, P. K., Madhu, V. R., Ghosh, S., Vivekanandan, E. and Meenakumari, B. 2010. Assessment of economic loss due to use of legal cod end mesh in multi-day trawlers in Gujarat. In: Meenakumari, B., Boopendranath, M. R. and Edwin, Leela, Sankar, T. V., Gopal, Nikita, and Ninan, George (Eds.), Coastal fishery resources of India conservation and sustainable ultisation. Society of Fisheries Technologists, Cochin, p. 370-377.

Nath, S. S., Bolte, J. P., Ross, L. G. and Aguilar-Manjarrez, J. 2000 Applications of geographical information systems (GIS) for spatial decision support in aquaculture. Aquac. Eng., 23: $233-278$

Rajitha, K., Mukherjee, C. K. and Vinu Chandran, R. 2007. Applications of remote sensing and GIS for sustainable management of shrimp culture in India. Aquac. Eng., 36: 1-17. 
Rekha, P. N., Ravichandran, P., Gangadharan, R., Bhatt, J. H., Panigrahi, A., Pillai, S. M. and Jayanthi, M. 2013. Assessment of hydrogeochemical characteristics of groundwater in shrimp farming area in coastal Tamil Nadu. Aquac. Int., 21: $1137-1153$.

Rekha, P. N., Gangadharan, R., Ravichandran, P., Mahalakshmi, P., Panigrahi, A. and Pillai, S. M. 2015. Assessment of impact of shrimp farming on coastal groundwater using geographical information system based analytical hierarchy process. Aquaculture, 491-506.

Singh, V., Patel, K., Patel, A., Mehmood, K., Kathota, J. and Kalubarme, M. H. 2012. Development of GIS for shrimp farms in coastal districts of Gujarat. Geospatial World. https://www.geospatialworld.net/article/development-of-gisfor-shrimp-farms-in-coastal-districts-of-gujarat/ (Accessed October 2015) 